\title{
Traffic-related air pollution is related to interrupter resistance in 4-year-old children
}

\author{
Esther Eenhuizen*, Ulrike Gehring*, Alet H. Wijga*, Henriette A. Smit", , \\ Paul H. Fischer ${ }^{\#}$, Michael Brauer ${ }^{+}$, Gerard H. Koppelman ${ }^{\S}$, Marjan Kerkhof ${ }^{f}$, \\ Johan C. de Jongste ${ }^{\star *}$, Bert Brunekreef*ף and Gerard Hoek*
}

ABSTRACT: Outdoor air pollution has been associated with decrements in lung function and growth of lung function in school-age children. Lung function effects have not been examined in preschoolers, with the exception of one study on minute ventilation in newborns. Our goal was to assess the relationship between long- and short-term exposure to traffic-related air pollution and interrupter resistance in 4-year-old children.

Lung function was measured using the interrupter resistance method in children participating in a Dutch birth cohort study. Long-term average air pollution concentrations of fine particulate matter, nitrogen dioxide and soot at the residential address at birth were assessed using land-use regression models. Daily average air pollution concentrations on the day of clinical examination were obtained from the Dutch National Air Quality Monitoring Network.

Significant associations were found between long-term average air pollution concentrations and interrupter resistance. Interrupter resistance increased by $0.04 \mathrm{kPa} \cdot \mathrm{s} \cdot \mathrm{L}^{-1}(95 \% \mathrm{Cl} 0.01-0.07)$ per interquartile range increase $\left(3.3 \mu \mathrm{g} \cdot \mathrm{m}^{-3}\right)$ in fine particle concentration. Short-term exposure was not associated with interrupter resistance.

Long-term exposure to traffic-related air pollution was associated with increased interrupter resistance in 4-year-old children, supporting previous birth cohort studies reporting effects of air pollution on subjectively reported respiratory symptoms in preschool children.

KEYWORDS: Air pollution, children, interrupter resistance, lung function, particulate matter

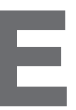
xposure to outdoor air pollution has been associated with increases in respiratory symptoms and decrements in lung function and growth of lung function in children [1-3]. In a recent review of short-term exposures, the concentration of particles with a diameter $<10 \mu \mathrm{m}$ (PM10) and nitrogen dioxide were associated with increased acute respiratory symptoms and lower peak expiratory flow [3]. Long-term average concentrations of particles $<10$ or $<2.5 \mu \mathrm{m}$ have also been associated with decrements in lung function and lung function growth [2]. Exposure to particulate air pollution has been associated with lower lung function growth in children aged 10-18 years in southern California (USA) [4-7] and 8-year-old children living in Mexico City (Mexico) [8]. There is also evidence from cross-sectional studies that particulate matter air pollution is associated with lower lung function [2]. Because most of these studies relied on spirometry, and since spirometry is difficult to perform in young children, there currently is virtually no data of the effects of air pollution exposure on lung function in children
$<6$ years old. One Swiss study reported significant associations between air pollution exposure during pregnancy and minute ventilation in newborns (5 weeks old) [9], but it is unclear whether these very early effects can be linked to the school-age spirometry findings. Birth cohort studies have shown effects of air pollution exposure on questionnaire-reported respiratory symptoms and allergic sensitisation in the first 4 years of life [10-12]. It is not known whether these effects are associated with impairment of lung function.

The interrupter resistance (Rint) technique is being used increasingly in preschool children to assess pulmonary function in paediatric practice and research [13-15]. This technique measures the resistance of the respiratory system by means of a brief interruption of the airflow during tidal breathing. Because this requires only minimal cooperation of the patient, the Rint technique can easily be used in preschool-age children [16, 17]. Recently, reference values have been proposed [14]. To date, Rint measurements have rarely been
AFFILIATIONS

*Institute for Risk Assessment

Sciences, Utrecht University, Utrecht,

${ }^{\#}$ National Institute for Public Health

and the Environment, Bilthoven,

"Julius Center for Health Sciences

and Primary Care, Utrecht University,

Utrecht,

§Beatrix Children's hospital,

University Medical Centre Groningen,

University of Groningen, Groningen,

${ }^{f}$ Dept of Epidemiology, University

Medical Centre Groningen, University

of Groningen, Groningen, and

**Dept of Paediatrics, Division of

Paediatric Respiratory Medicine, Erasmus University Medical Center -

Sophia Children's Hospital,

Rotterdam, The Netherlands.

+University of British Columbia,

Vancouver, BC, Canada.

CORRESPONDENCE

G. Hoek

PO Box 80178

3508 TD Utrecht

The Netherlands

E-mail: g.hoek@uu.nl

Received:

Feb 032012

Accepted after revision:

July 312012

First published online:

Nov 082012 
used to investigate effects of environmental exposures such as air pollution. In a study among school-aged and preschool children, Rint was $7-13 \%$ higher when parents smoked at least one cigarette per day versus nonsmoking parents [18].

We measured Rint in children aged 4 years in a large birth cohort study in the Netherlands [19], in which we had earlier reported associations between air pollution and allergic sensitisation and respiratory symptoms at ages 2 and 4 years $[10,11]$. The aim of this study was to assess the relationship between long- and short-term exposure to traffic-related air pollution and Rint.

\section{MATERIALS AND METHODS}

\section{Study population}

The Prevention and Incidence of Asthma and Mite Allergy (PIAMA) study is a prospective birth cohort study [20]. Females were recruited in 1996-1997 during their second trimester of pregnancy from a series of communities in the north, west and centre of the Netherlands. Nonallergic pregnant females $(n=2819)$ were invited to participate in a "natural history" study arm. Pregnant females identified as allergic through the screening questionnaire were allocated primarily to an intervention arm $(n=855)$ with a random subset $(n=472)$ allocated to the natural history arm. The intervention involved the use of mite-impermeable mattress and pillow covers. The study started with 3963 newborns. Yearly questionnaires completed by the parents provided data on demographic factors, respiratory symptoms and risk factors for asthma. All children of allergic mothers $(n=1173)$ and a sample of the children from nonallergic mothers $(n=635)$ were invited for a medical examination, including measurement of Rint [19]. The institutional review boards of the participating institutes approved the study protocol. Written informed consent was obtained from all participants.

Lung function data from clinical examinations at age 8 years [21] in association with air pollution are currently analysed in the framework of an international study (www.escapeproject.eu).

\section{Rint measurement}

Procedures for Rint measurement and quality criteria have been described in detail elsewhere [13, 19, 22]. Briefly, Rint was measured using the MicroRint (Micro Medical Ltd, Rochester, UK). Children were measured while breathing quietly, sitting upright and wearing a nose clip. The cheeks and chin were supported by the observer. All measurements were performed with a filter (Micro Medical Ltd) in place. Shutter closure was programmed at maximal expiratory tidal flow. Rint values were calculated as the median of at least five valid measurements out of 10 . The measurements were performed between October 18, 2000 and November 27, 2001 by trained investigators. Technicians were trained centrally to standardise the measurements in the three centres and supervised by one investigator to further standardise measurements by the three centres.

We finally included valid Rint data for 880 (49\%) out of the invited 1808 children in the analysis. A detailed flow chart of the exclusions is included in the online supplement of our earlier paper [19]. Briefly, no permission was obtained for medical examination from 529 children and no Rint measurement was made in 34 children. Rint measurements were not successful in a further 305 (24\%) children. Rejection criteria were tachypnoea, use of the vocal cords, leakage of the mouthpiece and extreme neck flexion or extension. Tracings of flow and pressure with invisible valve closure, valve closure that was not at the peak of expiration and horizontal or decreasing mouth pressure curves were rejected. Finally, we excluded children who used inhalation medication in the $12 \mathrm{~h}$ before Rint measurement, resulting in a total of 880 children for the final analysis. The children with valid Rint data did not differ in the distribution of population characteristics from the population invited for medical examination, with the exception of small differences in pet ownership and the presence of moulds in the home (table 1).

\section{Exposure assessment}

Long-term average concentrations of $\mathrm{NO}_{2}, \mathrm{PM} 2.5$ and soot at the birth address were assigned using land-use regression models previously described [10, 21, 23]. Briefly, regression models were developed based on air pollution measurements and predictor variables within a geographic information system. Air pollution measurements were performed between February 1999 and July 2000 at 40 sites spread over the Netherlands, including regional background, urban background and traffic sites [10, 23]. Annual average concentrations were obtained from the sampling campaign. The land-use regression models included region of the country (lower concentrations in the north), population density and traffic density close to the location [23]. The models explained 73, 81 and $85 \%$ of the variability of measured concentrations of PM2.5, soot and $\mathrm{NO}_{2}$, respectively [10, 21, 23]. These models were applied to calculate the air pollution concentrations at the birth addresses.

Daily average concentrations of PM10, black smoke and $\mathrm{NO}_{2}$ on the day of and before the medical examination were obtained from the Dutch National Air Quality Monitoring Network. We used data from a background location located centrally in the three study areas. Data on daily average outdoor temperature and humidity were available from the nearest station of the Royal Netherlands Meteorological Institute.

\section{Data analysis}

The association between long- and short-term exposure to air pollution and Rint was assessed by multiple linear regression, adjusting for sex, age at examination (days), height, weight, maternal smoking during pregnancy, any smoking in the child's home, use of gas for cooking, parental allergy, dampness in the home, education of the parents, season, temperature and humidity on the day of the Rint measurement. Sensitivity analyses were performed to test for the effect of cough on the test day, technician administering the test, region of the country and the (mite-impermeable mattress cover) intervention administered in part of the study population.

We further investigated the association between the Rint measurements at age 4 years and the presence of wheeze symptoms and a doctor diagnosis of asthma at age 8 years using logistic regression. Wheeze and asthma referred to the past 12 months [21]. We further assessed the association of Rint at age 4 years and forced expiratory volume in $1 \mathrm{~s}$ (FEV1) at age 8 years using linear regression with the natural logarithm of FEV1 as the dependent variable, and sex, the natural 
TABLE 1 Characteristics of the study population

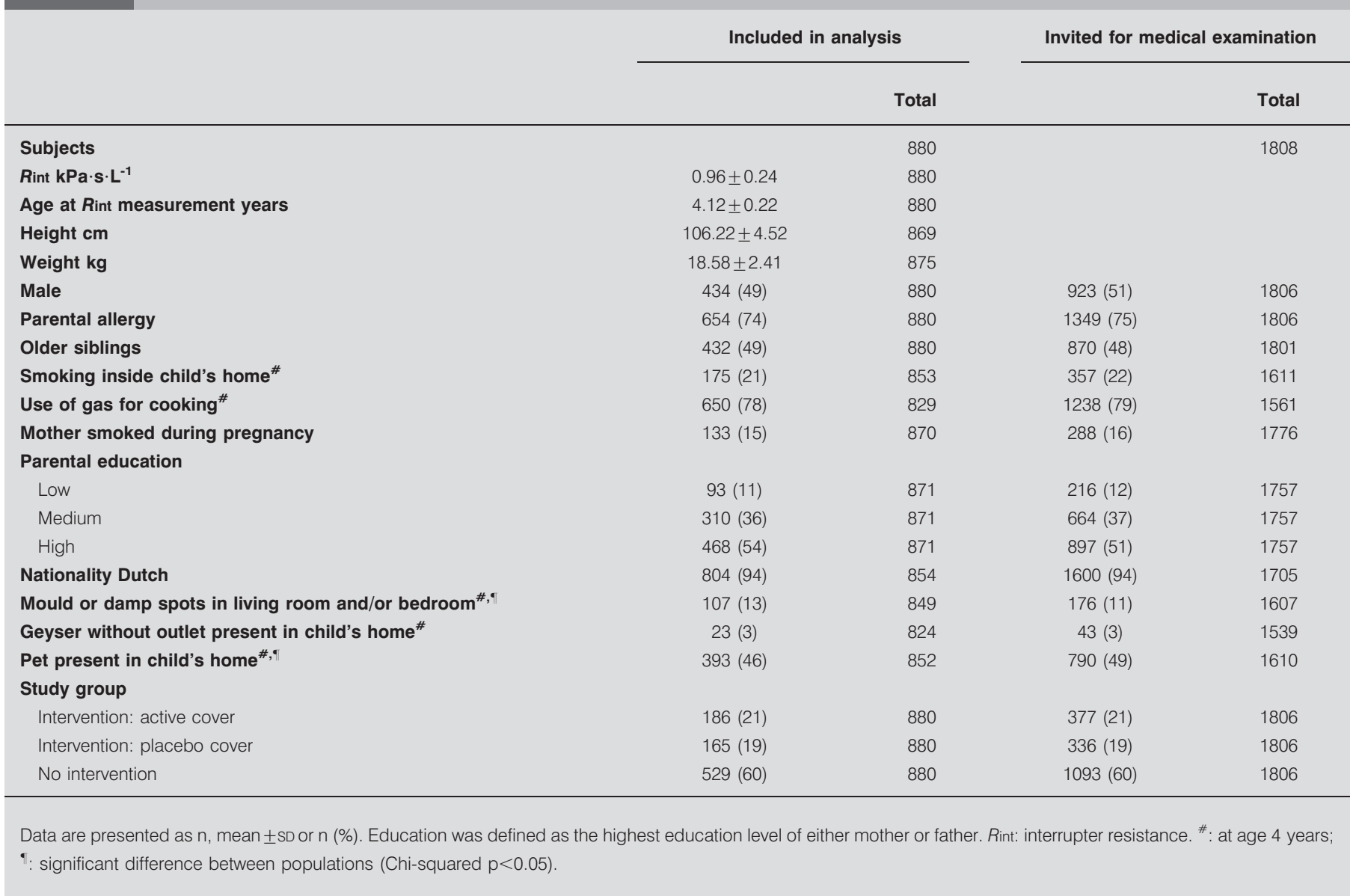

logarithm of age and weight (all at age 8 years) and Rint at age 4 years as independent variables. All analyses were performed using SAS statistical software (version 9.1; SAS Institute, Cary, NC, USA).

\section{RESULTS}

Table 1 shows the population characteristics of this study. $54 \%$ of the study population had parents with a high education level; only $11 \%$ had parents with a low education level.

TABLE 2 Distribution of air pollution substance concentrations

\begin{tabular}{|c|c|c|c|c|c|c|c|}
\hline \multicolumn{8}{|c|}{ Annual average at birth address } \\
\hline $\mathrm{PM} 2.5 \mu \mathrm{g} \cdot \mathrm{m}^{-3}$ & 880 & 13.54 & 14.89 & 17.32 & 16.90 & 18.15 & 24.58 \\
\hline Soot $10^{-5} \cdot \mathrm{m}^{-1}$ & 880 & 0.88 & 1.35 & 1.78 & 1.72 & 1.92 & 3.27 \\
\hline \multicolumn{8}{|c|}{ Day of Rint measurements } \\
\hline Black smoke $\mu \mathrm{g} \cdot \mathrm{m}^{-3}$ & 764 & 0.00 & 3.00 & 5.00 & 8.46 & 10.00 & 85.00 \\
\hline \multicolumn{8}{|c|}{ Day before Rint measurements } \\
\hline $\mathrm{NO}_{2} \mu \mathrm{g} \cdot \mathrm{m}^{-3}$ & 782 & 1.70 & 13.83 & 27.63 & 28.78 & 43.29 & 79.06 \\
\hline $\mathrm{PM} 10 \mu \mathrm{g} \cdot \mathrm{m}^{-3}$ & 827 & 8.89 & 21.33 & 27.12 & 29.97 & 35.16 & 110.96 \\
\hline Black smoke $\mu \mathrm{g} \cdot \mathrm{m}^{-3}$ & 769 & 0.00 & 3.00 & 5.00 & 7.54 & 10.00 & 64.00 \\
\hline
\end{tabular}


Three-quarters of the children had an allergic parent and very few children had non-Dutch nationality. The Rint test was successful in the large majority of children, indicating its feasibility at age 4 years. The mean $\pm \mathrm{SD}$ Rint was $0.96 \pm 0.24 \mathrm{kPa} \cdot \mathrm{s} \cdot \mathrm{L}^{-1}$. The children included in the analysis did not differ significantly from the children invited for medical examination, with the exception of small differences in pets and moulds in the home.

Table 2 shows the distribution of long- and short-term exposure to the air pollutants. Both long- and short-term exposure had a wide range within the study population. The modelled concentrations of $\mathrm{NO}_{2}, \mathrm{PM} 2.5$ and soot at the birth address were highly correlated (table 3 ). The concentrations of PM10 and black smoke on the test day and the day before the test had a very low correlation with the long-term exposure of the three pollutants at the birth address. $\mathrm{NO}_{2}$ levels on the test day and the day before the test were moderately correlated with long-term exposures.

\section{Association between air pollution and Rint}

A higher long-term average concentration of $\mathrm{NO}_{2}, \mathrm{PM} 2.5$ and soot at the birth address was associated with a higher Rint (table 4 and fig. 1). Adjustment for individual level confounders, season and weather on the test day reduced air pollution effect estimates only slightly. Figure 1 shows a monotonic increase of Rint with increasing concentration, with no suggestion of a threshold. Because of the very high correlations between the three pollutants, we did not specify two-pollutant models.

There was no significant association between short-term exposure to air pollutants and Rint (table 4) for the concentration on the test day, nor for the concentration on the day before the test day.

A model with long- and short-term exposure simultaneously in one model showed very similar associations to those presented in table 4 (data not shown).

\section{Effect modification by sex and parental allergy}

No significant differences in association between PM2.5 concentration at birth address and Rint were found between males and females $(p=0.74)$ and between children with allergic versus nonallergic parents $(\mathrm{p}=0.26)$. Effect estimates expressed for an interquartile range increase in PM2.5 \pm SE were $0.0251 \pm$ $0.0221 \mathrm{kPa} \cdot \mathrm{s} \cdot \mathrm{L}^{-1}$ for males versus $0.0430 \pm 0.0216 \mathrm{kPa} \cdot \mathrm{s} \cdot \mathrm{L}^{-1}$ for females and $0.0283 \pm 0.0178 \mathrm{kPa} \cdot \mathrm{s} \cdot \mathrm{L}^{-1}$ for children from allergic parents versus $0.0586 \pm 0.0292 \mathrm{kPa} \cdot \mathrm{s} \cdot \mathrm{L}^{-1}$ for children of nonallergic parents.

\section{Sensitivity analyses}

Associations between air pollution and Rint were not affected by further adjustment for the intervention in part of the study population, technician administering the test and cough reported on the day of the test (table 5). In total, 17 technicians administered the tests. When we adjusted additionally for study region (north, centre and west) air pollution effect estimates were not affected, but confidence intervals were much wider. The wider confidence intervals are explained by a reduction in exposure contrast, because region was a predictor variable used in the model that was used to calculate air pollution exposures. Confidence intervals also increased when we adjusted for technician, as different technicians were administering the tests in three study regions.

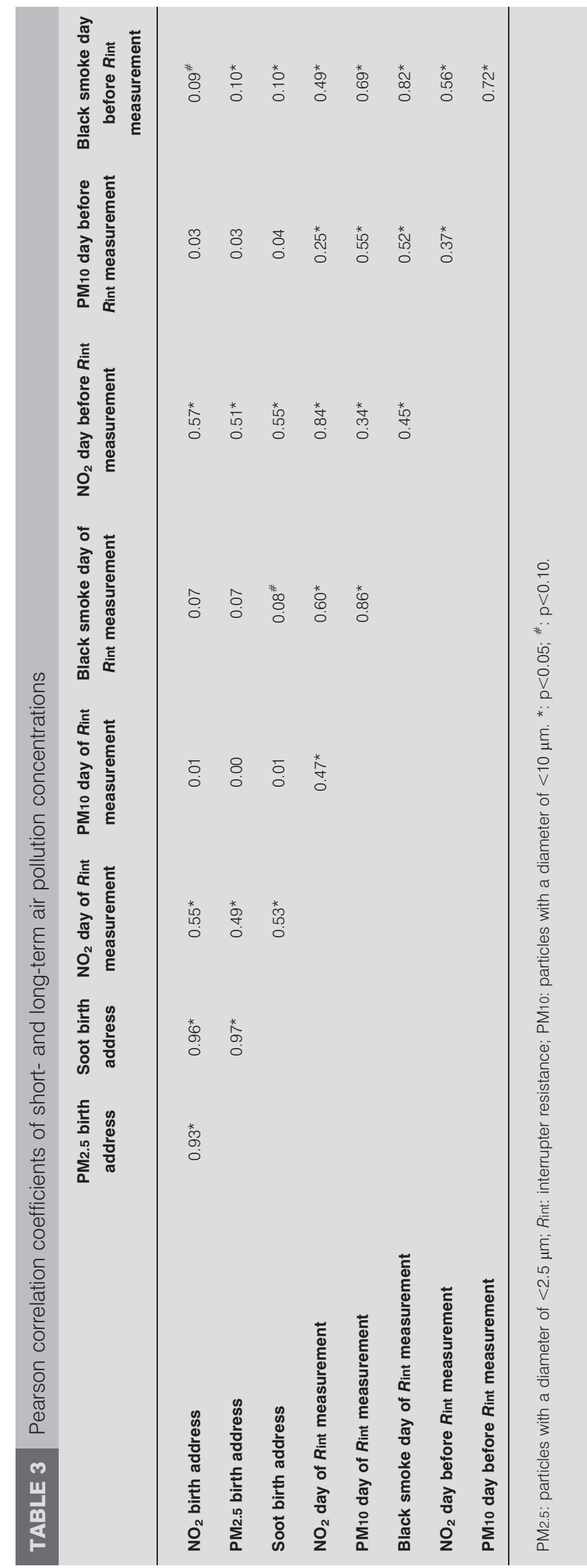




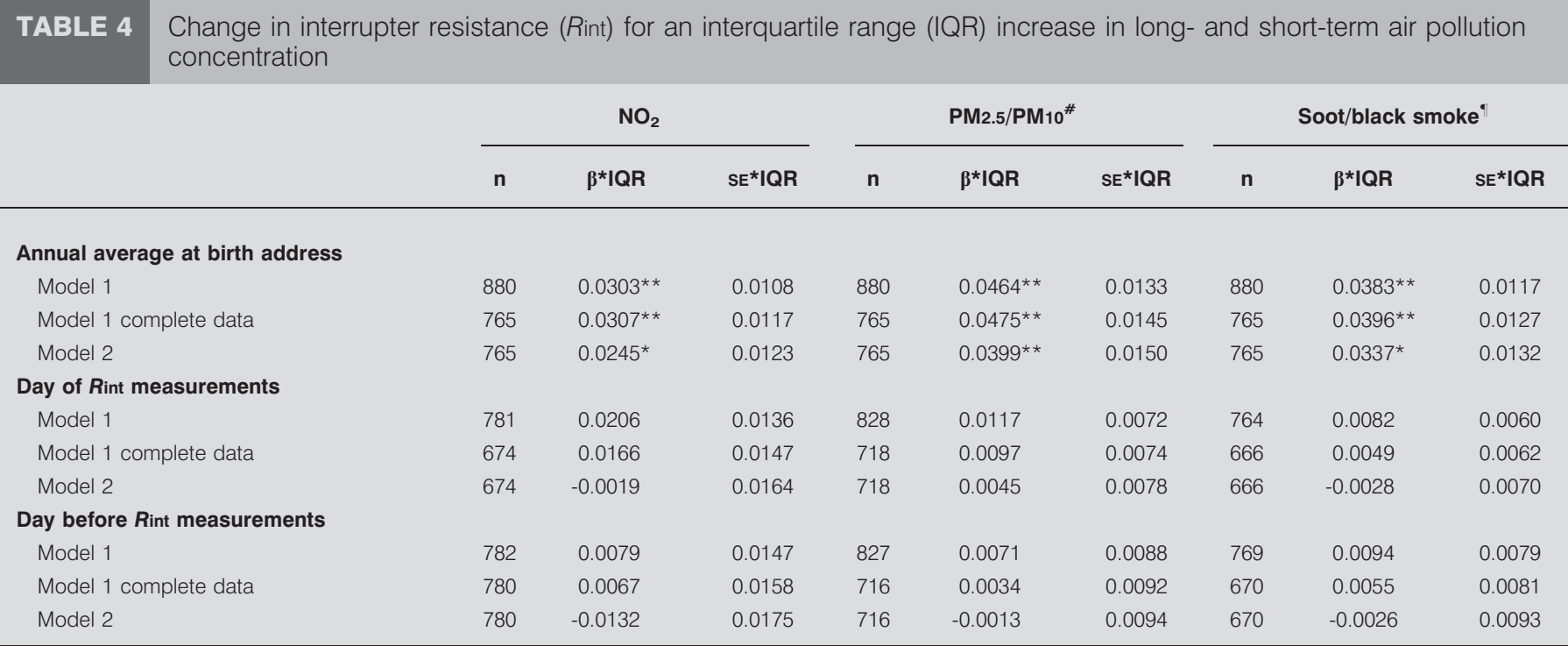

Change in Rint ( $\left.\mathrm{kPa} \cdot \mathrm{s} \cdot \mathrm{L}^{-1}\right)$ calculated by multiplying regression slopes ( $\beta$ ) from multiple linear regression with IQRs (table 2). Model 1: corrected for age and sex; model 1 complete data: model 1 adjusted for age and sex with complete confounder data (same $\mathrm{n}$ as model 2); model 2: model 1 plus correction for height, nationality, siblings, mother smoking during pregnancy, pets, mould/damp spots, smoking inside child's home, use of gas for cooking, geyser without outlet, parental allergy and education of parents, temperature, relative humidity and season. PM2.5: particles with a diameter of $<2.5 \mu \mathrm{m}$; PM10: particles with diameter of $<10 \mu \mathrm{m}$; ${ }^{\#}$ : data were available for PM2.5 for long-term exposure; data were available for PM10 for short-term exposure. ": data were available for soot for long-term exposure; data were available for black smoke for short-term exposure. Both are measures of black carbon particles using slightly different measurement methods. ${ }^{*}: p<0.05 ;{ }^{*}$ : $p<0.01$.

At the medical examination at age 4 years, 564 out of 880 children still lived at the birth address. An analysis for the children who still lived at their birth address showed very similar effect estimates as in the full study population: effect estimates $\pm \mathrm{SE}$ expressed per interquartile range increase in exposure were $0.0266 \pm 0.0161 \mathrm{kPa} \cdot \mathrm{s} \cdot \mathrm{L}^{-1}$ for $\mathrm{NO}_{2}, 0.0367 \pm 0.0194$ $\mathrm{kPa} \cdot \mathrm{s} \cdot \mathrm{L}^{-1}$ for PM2.5 and $0.0339 \pm 0.0173 \mathrm{kPa} \cdot \mathrm{s} \cdot \mathrm{L}^{-1}$ for soot.

\section{Association between Rint and respiratory health at age 8 years}

The Rint value at age 4 years was a significant predictor of presence of asthma and wheeze at age 8 years. Odds ratios (95\% CI) expressed for an increase of 0.05 Rint units (the approximate air pollution effect estimate) were 1.08 (1.03-1.13) for asthma and 1.07 (1.02-1.12) for wheeze. Odds ratios were not affected by adjustment for sex, height and weight. Rint at age 4 years was also significantly associated with a lower FEV1 at age 8 years, adjusting for age, sex, height and weight. A 0.05 -unit higher Rint value at age 4 years was associated with a $-0.78 \%(95 \% \mathrm{CI}-0.94-0.61)$ change in FEV1 at age 8 years.

\section{DISCUSSION}

Long-term exposure to traffic-related air pollution was significantly associated with Rint in 4-year-old children. No significant association with short-term exposure to air pollution was found.

We earlier reported in this study population an association between long-term air pollution exposure at the birth address and asthma symptoms at age 2 [10], 4 [11] and 8 years [21]. At age 4 years, we also reported associations between air pollution and sensitisation to major (food) allergens [11]. The current study shows that traffic-related air pollution was associated with increased Rint, an objective measure of lung function which reflects airway obstruction.

Associations between long-term exposure to ambient air pollution and lung function have been reported before in schoolchildren [2], but not in 4-year-old children. Most of the previous studies used spirometry, which cannot be performed reliably in children aged $<6$ years. We used the Rint technique, which has been shown to be useful in objectively assessing respiratory impairment in preschool children [14, 15]. The test has a good short-term repeatability [24] and hence one measurement of Rint can be used in studies assessing longterm exposure effects. Our study suggests that some of the associations reported in cross-sectional studies between ambient air pollution and lung function in schoolchildren may already be manifest at an earlier age. A study in Germany investigated the relationship between airway resistance in 6year-old children and total suspended particles (TSP) and distance of the home to a major road [25]. Airway resistance was measured with a body plethysmograph. TSP was not consistently associated with airway resistance, but children living within $50 \mathrm{~m}$ of a main road had a $7 \%$ higher airway resistance [25]. Our results further suggest that the Rint method could be a useful tool to assess functional effects at a young age for other risk factors such as environmental tobacco smoke, gas cooking and biological contaminants as well.

The magnitude of the observed association between air pollution and Rint was moderate.

An interquartile range increase in the PM2.5 concentration was associated with an increase in $R$ int of $0.04 \mathrm{kPa} \cdot \mathrm{s} \cdot \mathrm{L}^{-1}$, which 

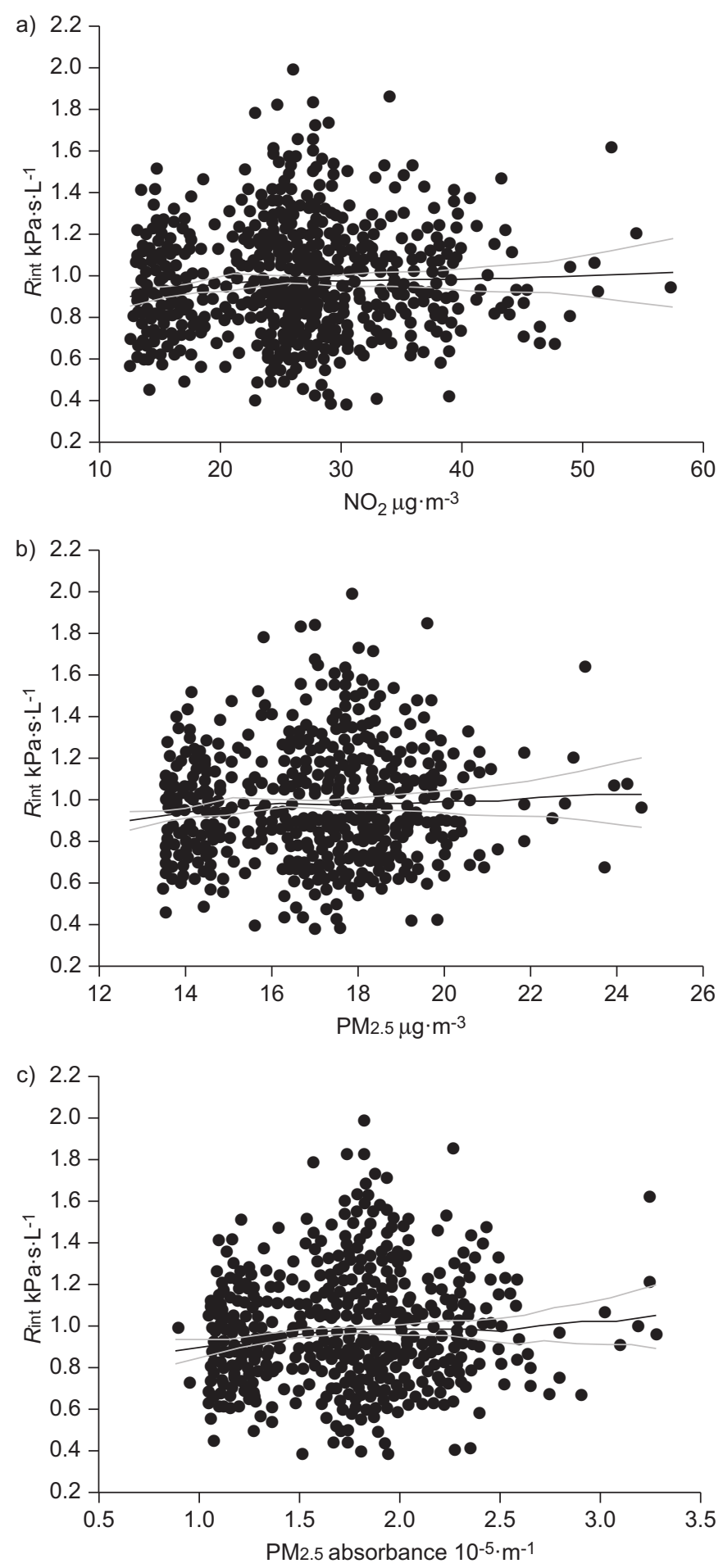

FIGURE 1. Scatter plot of the relationship between interrupter resistance (Rint) and a) annual average concentration of $\mathrm{NO}_{2}$; b) particles with a diameter of $<2.5 \mu \mathrm{m}$ (PM2.5); and c) soot at the birth address. Solid lines are Loess smoothers (span=0.6) with $95 \% \mathrm{Cl}$ (point-wise $1.96 \mathrm{SE}$ bands).

corresponds to $\sim 4 \%$ of the population mean Rint. Another study in the same study population showed significant differences in Rint between children with different wheezing phenotypes, which were about three times higher than the increase associated with an interquartile range of PM2.5 observed in the current study [19]. In a study among schooland preschool children, smoking of the parents was associated with a $7-13 \%$ increase in Rint [18]. In our study we did not find any association between smoking and Rint, possibly due to low smoking rates in the birth cohort. Increased Rint at age 4 years was a significant predictor of asthma and wheeze risk and lung function at age 8 years, adding to the potential importance of our findings.

We did not observe an association between Rint and air pollution exposure on the day of the test or the day before the test. Hence the observed associations with long-term exposure do not reflect only a transient short-term exposure effect. Since our study design consisted of one Rint measurement per subject and air pollution effects had to be larger than the between-subject variability, we cannot exclude the possibility that small short-term effects on Rint are present. Exposure misclassification because of the use of one background site to represent short-term air pollution concentrations in the three areas may have contributed to the lack of effect. This is unlikely to be a major bias, as studies have found high temporal correlations between concentrations measured at background sites [26].

\section{Limitations}

We used air pollution exposure at the birth address as our exposure variable, as in previous analyses of this study [10, 11, 21]. Because a large fraction of our study population at age 4 years still lived at their birth address, we cannot disentangle whether it is the exposure at birth or at a later age which drives the associations with Rint. One study in Switzerland reported significant associations between PM10 and $\mathrm{NO}_{2}$ exposure of the mother during pregnancy and minute ventilation measured in newborns 5 weeks of age [9]. We report associations between three pollutants assessed for the birth address. Because of the high correlation between modelled $\mathrm{PM} 2.5, \mathrm{NO}_{2}$ and soot we cannot disentangle which of the pollutants is driving the observed association, as observed before for this study population [10]. We interpret our findings as showing associations between trafficrelated air pollution and lung function, with the three pollutants being indicators of the complex ambient mixture.

The children included in this analysis were not a representative sample of the general population of children from the study areas, especially because children from allergic mothers were overrepresented in the selection of the cohort [20]. However, children included in this analysis did not differ in important covariates from the cohort of children invited for medical examination. We did not find a significant difference in air pollution effect estimates between children with and without allergic parents, so the estimates for this population may apply to the general population of children.

We conclude that long-term exposure to traffic-related air pollution was associated with increased Rint and, hence, reduced airway patency in 4-year-old children.

\section{SUPPORT STATEMENT}

This study was funded by the Netherlands Organisation for Health Research and Development; the Netherlands Organisation for Scientific Research; the Netherlands Asthma Fund; the Netherlands Ministry of Spatial Planning, Housing and the Environment; and the Netherlands Ministry of Health, Welfare and Sport. 


\begin{tabular}{|c|c|c|c|c|c|c|c|c|c|c|}
\hline \multirow[t]{3}{*}{ TABLE 5} & \multicolumn{10}{|c|}{$\begin{array}{l}\text { Change in interrupter resistance (Rint) for an interquartile range (IQR) increase in long-term air pollution concentration: } \\
\text { sensitivity analysis }\end{array}$} \\
\hline & & \multicolumn{3}{|c|}{$\mathrm{NO}_{2}$} & \multicolumn{3}{|c|}{ PM2.5 } & \multicolumn{3}{|c|}{ Soot } \\
\hline & & $\mathbf{n}$ & $\beta * I Q R$ & $S E * I Q R$ & $\mathbf{n}$ & $\beta * I Q R$ & $S E * I Q R$ & $\mathbf{n}$ & $\beta^{\star} I Q R$ & $S E * I Q R$ \\
\hline \multicolumn{2}{|c|}{ Model 2 (main model) } & 765 & $0.0245^{\star}$ & 0.0123 & 765 & $0.0399 *$ & 0.0150 & 765 & $0.0337^{\star}$ & 0.0132 \\
\hline \multicolumn{2}{|c|}{ Model 2 + technician Rint } & 765 & 0.0283 & 0.0184 & 765 & $0.0432^{\#}$ & 0.0247 & 765 & $0.0376^{\#}$ & 0.0198 \\
\hline \multicolumn{2}{|c|}{ Model $2+$ region of the country } & 765 & 0.0248 & 0.0192 & 765 & 0.0400 & 0.0271 & 765 & $0.0368^{\#}$ & 0.0210 \\
\hline
\end{tabular}

\section{STATEMENT OF INTEREST}

None declared.

\section{REFERENCES}

1 Brunekreef B, Holgate ST. Air pollution and health. Lancet 2002; 360: 1233-1242.

2 Götschi T, Heinrich J, Sunyer J, et al. Long-term effects of ambient air pollution on lung function: a review. Epidemiology 2008; 19: 690-701.

3 Weinmayr G, Romeo E, De Sario M, et al. Short-term effects of $\mathrm{PM} 10$ and $\mathrm{NO}_{2}$ on respiratory health among children with asthma or asthma-like symptoms: a systematic review and meta-analysis. Environ Health Perspect 2010; 118: 449-457.

4 Gauderman WJ, Vora H, McConnell R, et al. Effect of exposure to traffic on lung development from 10 to 18 years of age: a cohort study. Lancet 2007; 369: 571-577.

5 Gauderman WJ, Avol E, Gilliland F, et al. The effect of air pollution on lung development from 10 to 18 years of age. $N$ Engl J Med 2004; 351: 1057-1067.

6 Gauderman WJ, McConnell R, Gilliland F, et al. Association between air pollution and lung function growth in southern California children. Am J Respir Crit Care Med 2000; 162: 1383-1390.

7 Gauderman WJ, Gilliland GF, Vora H, et al. Association between air pollution and lung function growth in southern California children: results from a second cohort. Am J Respir Crit Care Med 2002; 166: 76-84.

8 Rojas-Martinez R, Perez-Padilla R, Olaiz-Fernandez G, et al. Lung function growth in children with long-term exposure to air pollutants in Mexico City. Am J Respir Crit Care Med 2007; 176: 377-384.

9 Latzin P, Röösli M, Huss A, et al. Air pollution during pregnancy and lung function in newborns: a birth cohort study. Eur Respir J 2009; 33: 594-603.

10 Brauer M, Hoek G, Van Vliet P, et al. Air pollution from traffic and the development of respiratory infections and asthmatic and allergic symptoms in children. Am J Respir Crit Care Med 2002; 166: 1092-1098.

11 Brauer M, Hoek G, Smit HA, et al. Air pollution and development of asthma, allergy and infections in a birth cohort. Eur Respir $J$ 2007; 29: 879-888.

12 Gehring U, Cyrys J, Sedlmeir G, et al. Traffic-related air pollution and respiratory health during the first 2 years of life. Eur Respir J 2002; 19: 690-698.
13 Merkus PJ, Mijnsbergen JY, Hop WC, et al. Interrupter resistance in preschool children: measurement characteristics and reference values. Am J Respir Crit Care Med 2001; 163: 1350-1355.

14 Merkus PJ, Stocks J, Beydon N, et al. Reference ranges for interrupter resistance technique: the Asthma UK initiative. Eur Respir J 2010; 36: 157-163.

15 Beydon N, Davis SD, Lombardi E, et al. An official American Thoracic Society/European Respiratory Society Statement: pulmonary function testing in preschool children. Am J Respir Crit Care Med 2007; 175: 1304-1345.

16 Caudri D, Wijga AH, Hoekstra MO, et al. Prediction of asthma in symptomatic preschool children using exhaled nitric oxide, Rint and specific IgE. Thorax 2010; 65: 801-807.

17 Child F. The measurement of airways resistance using the interrupter technique (Rint). Paediatr Respir Rev 2005; 6: 273-277.

18 Kooi EM, Vrijlandt EJ, Boezen HM, et al. Children with smoking parents have a higher airway resistance measured by the interruption technique. Pediatr Pulmonol 2004; 38: 419-424.

19 Brussee JE, Smit HA, Koopman LP, et al. Interrupter resistance and wheezing phenotypes at 4 years of age. Am J Respir Crit Care Med 2004; 169: 209-213.

20 Brunekreef B, Smit J, de Jongste J, et al. The prevention and incidence of asthma and mite allergy (PIAMA) birth cohort study: design and first results. Pediatr Allergy Immunol 2002; 13: Suppl. 15, 55-60.

21 Gehring U, Wijga AH, Brauer M, et al. Traffic-related air pollution and the development of asthma and allergies during the first 8 years of life. Am J Respir Crit Care Med 2010; 181: 596-603.

22 Beelen RM, Smit HA, van Strien RT, et al. Short and long term variability of the interrupter technique under field and standardised conditions in 3-6 year old children. Thorax 2003; 58: 761-764.

23 Brauer M, Hoek $G$, van Vliet $P$, et al. Estimating long-term average particulate air pollution concentrations: application of traffic indicators and geographic information systems. Epidemiology 2003; 14: 228-239.

24 Beydon N, M'Buila C, Bados A, et al. Interrupter resistance shortterm repeatability and bronchodilator response in preschool children. Respir Med 2007; 101: 2482-2487.

25 Sugiri D, Ranft U, Schikowski T, et al. The influence of large-scale airborne particle decline and traffic-related exposure on children's lung function. Environ Health Perspect 2006; 114: 282-288.

26 Hoek G, Brunekreef B, Verhoeff A, et al. Daily mortality and air pollution in the Netherlands. J Air Waste Manag Assoc 2000; 50: 1380-1389. 